\title{
DSM-IV Axis I Psychopathology in Males with Non-Paraphilic Hypersexual Disorder
}

\author{
Martin P. Kafka ${ }^{1,2}$ \\ Published online: 9 July 2015 \\ (C) Springer International Publishing AG 2015
}

\begin{abstract}
Non-paraphilic hypersexual disorder, also described as sexual addiction/compulsivity, is associated with significant, adverse, social, and public health consequences. Despite differences in their appellative designation, this condition is commonly associated with psychiatric Axis I (and Axis II) comorbidities. The extant and recent clinical and research describing concurrent Axis I diagnoses is reviewed. Despite methodological differences in assessment, hypersexual disorder shares a high degree of Axis I comorbidity with both unipolar and bipolar mood disorders, anxiety disorders, especially generalized and social anxiety, attention-deficit hyperactivity disorder - inattentive subtype, and psychoactive substance-abuse disorders. The aforementioned Axis I disorders, like hypersexual disorder, also share early age of onset and association with other sensation-seeking and risk-taking behaviors.
\end{abstract}

Keywords Axis I comorbidity · Mood disorder · Depression · Hypomania $\cdot$ Bipolar $\cdot$ Attention deficit-hyperactivity disorder · Social anxiety disorder · Generalized anxiety disorder - Sexual addiction - Sexual compulsivity · Paraphilia-related disorder - Behavioral addiction . Hypersexuality

This article is part of the Topical Collection on Sex and Addiction

Martin P. Kafka

mpkafka@rcn.com

1 Department of Psychiatry, Harvard Medical School, Boston, MA, USA

22 Mill St Suite \#306, Arlington, MA 02476, USA

\section{Introduction}

Non-paraphilic hypersexual disorder (HD) [1, 2], also characterized as sexual compulsivity/addiction and paraphiliarelated disorders, includes a group of sexual behavior disorders whose placement in our psychiatric nosology remains controversial. A fundamental characteristic of these conditions is volitional impairment, often characterized as "loss of control" associated with clinically significant adverse consequences. Persons presenting for clinical care, predominantly males, characteristically describe very time-consuming fantasies and urges or cravings associated with an intensity of their sexual arousal. In addition, persons suffering from this condition frequently describe an increase in the urgency and intensity of these fantasies, urges and behaviors in response to external stressors and/or dysphoric affects, such as anxiety, depression, boredom or irritability. Last, problematic sexual behaviors may escalate in frequency or intensity and involve increased risk-taking or intensified sensation-seeking. Although persons presenting clinically with hypersexual disorder are typically in their third or fourth decade [2], the presence of increased frequency and intensity of sexual arousal and fantasies typically are often reported with the onset of adolescence $[3,4]$.

\section{Method}

A Medline and PsychInfo database literature search was performed in September 2014 using PubMed, and published articles were retrieved using search terms including: "< sexual behavior>", "sexual addiction", "sexual compulsivity" "compulsive sexual behavior", "paraphilia-related disorder", "sexual impulsivity", "behavioral addiction", and "hypersexual" combined with "Axis I" and "comorbidity". Thirty relevant 
articles were retrieved. Small sample case reports, including cases associated with exogenous psychoactive substance use or medication prescription, were excluded. Links to important associated articles were retrieved in addition.

\section{Literature Review}

Black and associates [4] assessed 36 male $(n=28)$ and female $(n=8)$ participants to an advertisement for "compulsive sexual behavior"; Black administered the Diagnostic Interview Schedule for DSM-III-R disorders (Axis I) [5]. The Axis I disorders reported included a lifetime prevalence of any psychoactive substance abuse (64\%, primarily alcohol abuse), any anxiety disorder (50\%, especially phobic disorders), any mood disorder (39\%, major depression and dysthymia), and an unspecified but significant total incidence of impulse control disorders, including compulsive buying. Lifetime obsessive-compulsive disorder was reported by $14 \%$ of that sample - the highest prevalence reported in any of the reviewed samples. Eighty-three percent of the sample had at least one lifetime Axis I comorbid diagnosis. The sample was not psychiatrically evaluated for adult attention-deficit hyperactivity disorder or bipolar spectrum disorders.

Kafka and Hennen [6] and Kafka and Prentky [7, 8], in three outpatient male samples (total $n=240$ ), reported that the typical male with paraphilia-related disorders (without paraphilias) had multiple lifetime Axis I disorders, including any mood disorder (61-65\%, especially dysthymic disorder), any psychoactive substance abuse (39-47\%, especially alcohol abuse), any anxiety disorder (43-46\%, especially social phobia), attention-deficit hyperactivity disorder, inattentive subtype (17-19\%), and any impulse control disorder (7$17 \%$ ), especially the atypical impulse control disorder reckless driving. It is of clinical interest that males with paraphiliarelated disorders did not statistically significantly differ from males with paraphilias in the lifetime prevalence of mood, anxiety, psychoactive substance abuse, or impulse control disorders. Lifetime comorbidity with obsessive-compulsive disorder was low (0-11\%) in all three reports. Between 85 and $90 \%$ of the samples met lifetime diagnostic criteria for at least one non-sexual comorbid Axis I disorder. In the second [8] and third reports [6], the additional assessment, ascertained retrospectively, of childhood attention-deficit hyperactivity disorder (ADHD) did statistically distinguish the PA (prevalence of ADHD was 36-50\%) from the PRD group (17$19 \%$ ). The inattentive subtype of childhood-onset ADHD was predominant in PRD males while ADHD-combined subtype was more prevalent in paraphilic men. Those samples were not clinically assessed for bipolar spectrum disorders.

Raymond et al. [9] assessed current and lifetime Axis I comorbidity utilizing the Structured Clinical Interview for
DSM-III-R-patient version [10] in a sample of 25 participants (23 males, 2 females) to newspaper advertisement soliciting persons with compulsive/addictive sexual behaviors. Axis I lifetime comorbidity was $100 \%$. The most common class of disorders was any anxiety disorder (96\%), especially social phobia (21\%) and generalized anxiety disorder (17\%). Any substance-abuse disorder (71\%), especially alcohol (63\%) and cannabis (38\%), and any mood disorder (71\%), especially major depression (58\%), dysthymia (8\%), and bipolar disorder $(8 \%)$, were the second most prevalent classes of Axis I psychiatric disorders. Impulse control disorders (38 \%), especially kleptomania ( $13 \%$ ) and intermittent explosive disorder $(13 \%)$, were diagnosed. Their sample endorsed both impulsive and compulsive traits but, as in some of the previous mentioned reports, the sample prevalence of lifetime OCD was modest $(8 \%)$.

Reid and colleagues [11, 12] administered psychological diagnostic scales (e.g., MMPI II [13] and SCL-90 [14]) to several samples of outpatient treatment-seeking males. For example, 59 males seeking psychological help for nonparaphilic hypersexual behaviors were compared with a control group of 54 college-age men. Although their initial study did not specifically assess Axis I comorbidity, the hypersexual sample reported more interpersonal sensitivity/depressive (neuroticism) symptoms, social alienation, and obsessive characteristics and preoccupation than the control group.

In addition, Reid and associates administered rating scales specifically for the assessment of attention-deficit hyperactivity disorder (Conner's Adult ADHD Rating Scale [15], the Adult ADHD Self-Report Scale [16], and the Wender Utah Rating Scale [17]), in several samples of treatment-seeking males. They reported that between $23-27 \%$ of their samples met criteria for lifetime ADHD, especially the inattentive subtype. Males with ADHD also were likely to have comorbid mood and anxiety disorders. $[18,19 \bullet \cdot]$. It is noteworthy that the latter sample included 361 consecutively evaluated males, the largest clinical sample to-date.

Morganstern, Muench, and associates [20] administered the Structured Clinical Interview for DSM-IV Mood and Psychotic Disorder modules [21] to 183 gay and bisexual males and reported that $65.5 \%$ met diagnostic criteria for a comorbid Axis I disorder including substance dependence (35\%, including alcohol, $20.2 \%$ ), mood disorders, $32.8 \%$, especially depression (32.8\%). Notably, as with other aforementioned studies that reported mood disorder comorbidity, only $2.6 \%$ met criteria for hypomania or mania (but again, only bipolar I and II were assessed, personal communication 10.06.2012).

Scanavino, Ventunaec and associates [22•] explored compulsive sexual behavior in a Brazilian male outpatient sample of 86 males by administering the Multi-Axial International Neuropsychiatric Interview (M.I.N.I.) [23]. They reported that anxiety disorders ( $46.5 \%$, especially generalized anxiety disorder, $32.6 \%$ ), mood disorders (36.1\%, especially major 
depression, $23.5 \%$ ), and psychoactive substance-abuse disorders (especially alcohol abuse/dependence, $10.5 \%$ ), were the most prevalent Axis I comorbidities. They did not assess ADHD and did not report hypomania lasting less than 4 days.

Sensation-seeking and risk-taking are essential features in hypomanic and manic states [24], but the broader concept of bipolar spectrum disorders were not included in the aforementioned articles reviewed. DiNicola and associates [25] included cyclothymic disorder as well as bipolar I and II in their study of 158 outpatients with bipolar disorders and behavioral addictions. They drew comparison with a matched control group of 200 non-bipolar subjects. One third of their sample reported at least a single behavioral addiction, including sexual addiction as determined by the Sexual Addiction Screening Test [26]. Only five subjects, however, endorsed scores for current sexual addiction. This may have been a low estimate because most subjects were currently receiving pharmacological treatments for bipolar disorder.

\section{Discussion}

Putative pathophysiological models describing non-paraphilic hypersexual behaviors all include the observation that repetitive hypersexual behaviors are typically associated with dysphoric affects, such as a depressed or anxious mood, boredom, or irritability. In this literature review, Axis I psychiatric diagnoses, especially mood disorders, anxiety disorders, psychoactive substance-abuse disorders, and attention-deficit hyperactivity disorders are consistently reported to be prevalent among males with sexual addiction/compulsivity, paraphiliarelated disorders, and hypersexual disorder. Dysphoric affects are intrinsic components of the operational definition of these aforementioned neuropsychiatric disorders. Sensationseeking and risk-taking can be associated with unipolar and bipolar mood disorders and ADHD as well. On the other hand, clearly not all persons affected by the aforementioned Axis I co-morbidities developed problematic hypersexuality. Other important factors such as developmental adversity, including early exposure to sexual behavior or pornographic materials, most likely contribute a significant role as well in the development of this type of sexual psychopathology.

Mood disorders are typically associated with dysregulation or change (either an increase or a decrease) of sleep and appetite and level of activity. Diminished sexual interest and decreased enacted sexual behavior are typically included as part of the operational definition of a major depressive episode [27]. Although increased sexual interest and enacted behavior has been noted in association with depressive disorders [28-31], this literature is less well established, and the association may appear clinically counterintuitive. Increased sexual behavior may play a self-medicating role while a subject is anxious or depressed, and mood disorder associated perturbations in neurotransmitters could also contribute to persisting hypersexuality [32].

Bipolar spectrum disorders may be significantly prevalent in some clinical samples of treatment-seeking males. As was evidenced in this review, however, despite multiple reports by different investigators utilizing different (but validated) psychiatric assessment instruments, only bipolar I and II were consistently diagnostically assessed, and a broader spectrum for bipolarity was not included. It is widely recognized that DSM-IV-TR defined hypomanic episodes, lasting four or more days can be associated with "increased sexual drive, fantasies and behavior, including 'sexual indiscretions"'. Recent data from large and representative United States epidemiological samples, however, have reported that the mean duration of hypomanic episodes may be significantly less than four or more days $[33,34]$. Hypomanic symptoms while "depressed" may also complicate the clinical assessment of "unipolar" depression [35]. This investigator contends that the absence of studies including the broader "bipolar spectrum" is a significant limitation of the current research literature. For example, in this investigator's clinical practice, in 85 consecutively evaluated males with hypersexual disorders, $37.6 \%$ were diagnosed with lifetime bipolar mood disorders utilizing the MINI-Plus v.6.0 [36]. One-half of those diagnosed with bipolar disorder $(n=16)$ met diagnostic criteria for cyclothymic disorder or bipolar N.O.S. (MPK, unpublished data 2014). The presence of brief recurrent hypomanic episodes complicate establishing a clear distinction between a mood disorder "episode" from a recurrent sexual behavior associated with risk-taking that becomes associated with personal distress or socially adverse consequences [37].

The recognition of Axis I comorbidities associated with non-paraphilic hypersexual behavior has important potential treatment implications. For example, psychological treatments targeting affective states associated with hypersexual behavior $[31,38]$ and pharmacological treatments addressing Axis I psychiatric comorbidity [39] can mitigate these behaviors but, again, the literature in support of these interventions requires greater methodological rigor and improved prospective research design.

This reviewed literature has several methodological limitations. Most importantly, although there is a growing research literature describing non-paraphilic hypersexual disorder, the rating instruments to diagnose such disorders as well as the diagnostic instruments to assess Axis I comorbidities varied substantially across studies. In addition, it would be of interest to determine whether specific behavioral subtypes of hypersexual disorder are associated with specific Axis I comorbidities. For example, would males whose sole Axis I disorder is ADHD be more likely to engage in Internet pornographydependence because such images are literally a click away and would not require anticipatory planning and organizational skills? Conversely, would men afflicted by social anxiety 
disorder be less likely to engage in protracted promiscuous behavior because of interpersonal dread? These more sharply defined issues have not been adequately addressed in the research literature reviewed for this manuscript. This author is hopeful that a finer delineation of hypersexual disorder (sexual compulsivity/addiction), its behavioral subtypes, developmental antecedents, and Axis I comorbidities will be the subject of further research reports.

\section{Compliance with Ethics Guidelines}

Conflict of Interests Martin P. Kafka, MD, declares that he has no conflict of interest.

Human and Animal Rights and Informed Consent This article does not contain any studies with human or animal subjects performed by the author.

\section{References}

Papers of particular interest, published recently, have been highlighted as:

- Of importance

•- Of major importance

1. Kafka MP. Hypersexual disorder: a proposed diagnosis for DSM-V. Arch Sex Behav. 2010;39:377-400.

2. Reid RC, Carpenter BN, Hook JN, Garos S, Manning JC, Gilliland $\mathrm{R}$, et al. Report of findings from a DSM-5 field trial for hypersexual disorder. J Sex Med. 2012;9:2868-77.

3. Kafka MP. Hypersexual desire in males: an operational definition and clinical implications for men with paraphilias and paraphiliarelated disorders. Arch Sex Behav. 1997;26:505-26.

4. Black DW, Kehrberg LLD, Flumerfelt DL, Schlosser SS. Characteristics of 36 subjects reporting compulsive sexual behavior. Am J Psychiatry. 1997;154:243-9.

5. Robins LN, Helzer JE, Cottler L, Golding E. National Institute of Mental Health Diagnostic Interview Schedule, version III, revised (DIS III-R). St Louis: Washington University School of Medicine; 1989.

6. Kafka MP, Hennen J. A DSM IV Axis I comorbidity study of males $(n=120)$ with paraphilias and paraphilia-related disorders. Sex Abus: J Res Treat. 2002;14:349-66.

7. Kafka MP, Prentky RA. Preliminary observations of DSM III-R Axis I comorbidity in men with paraphilias and paraphilia-related disorders. J Clin Psychiatry. 1994;55:481-7.

8. Kafka MP, Prentky RA. Attention deficit hyperactivity disorder in males with paraphilias and paraphilia-related disorders: a comorbidity study. J Clin Psychiatry. 1998;59:388-96.

9. Raymond NC, Coleman E, Miner MH. Psychiatric comorbidity and compulsive/impulsive traits in compulsive sexual behavior. Compr Psychiatry. 2003;44:370-80.

10. Spitzer RL, Williams JB, Gibbon M, First MB. Structured Clinical Interview for DSM-III-R-Patient Edition (SCID-P, version 1.0). Washington D.C.: 1990.

11. Reid RC, Carpenter BN. Demoralization, hypomanic activation, and disconstraint scoreson MMPI-2 scales as significant predictors of hypersexual behavior. J Sex Addict Compulsivity. 2009;16:17389.

12. Reid RC, Carpenter BN. Exploring relationships of psychopathology in hypersexual patients using the MMPI-2. J Sex Marital Ther. 2009;35:294-310.

13. Butcher JN, Dahlstrom WG, Graham JR, Tellegen A, Kaemmer B. The Minnesota Multiphasic Personality Inventory-2 (MMPI-2): Manual for administration and scoring. Minneapolis: University of Minnesota Press; 1989.

14. Derogatis LR. Manual for the symptom checklist-90. Baltimore: Johns Hopkins University School of Medicine; 1977.

15. Connors CK. Attention deficit hyperactivity disorder: assessment and treatment for children and adolescents. Toronto: MultiHealth Systems; 1994.

16. Kessler RC, Adler L, Ames M, Demler O, Faraone S, Hiripi E, et al. The World Health Organization Adult ADHD Self-Report Scale (ASRS): a short screening scale for use in the general population. Psychol Med. 2005;35:245-56.

17. Ward MF, Wender PH, Reimherr FW. The Wender Utah Rating Scale: an aid in the retrospective diagnosis of childhood attention deficit hyperactivity disorder. Am J Psychiatry. 1993;150:885-9.

18. Reid RC. Assessing readiness to change among clients seeking help for hypersexual behavior. Sex Addict Compulsivity. 2007;14:16786.

19.• Reid RC, Carpenter BN, Gilliland R, Karim R. Problems of selfconcept in a patient sample of hypersexual men with attentiondeficit disorder. J Addict Med. 2011;5:134-40. The largest consecutive sample in the current research litertature.

20. Morgenstern J, Muench F, O' Leary A, Wainberg M, Parsons JT, Hollander E, et al. Non-paraphilic compulsive sexual behavior and psychiatric co-morbidities in gay and bisexual men. Sex Addict Compulsivity. 2011;18:114-34.

21. First MB, Spitzer RL, Gibbon M. Structured Clinical Interview for DSM-IV Axis I Disorders-Patient Edition. New York: New York State Psychiatric Institute: Biometric Research; 1996.

22. Scanavino Mde T, Ventuneac A, Abdo CH, Tavares H, do Amaral ML, Messina B, et al. Compulsive sexual behavior and psychopathology among treatment-seeking men in Sao Paulo, Brazil. Psychiatry Res. 2013;209:518-24. The largest non-NorthAmerican sample reported in the literature.

23. Sheehan DV, Lecrubier Y, Harnett-Sheehan K, Amorim P, Janavs J, Weiller E, et al. The Mini International Neuropsychiatric Interview: the development and validation of a structured diagnostic psychiatric interview. J Clin Psychiatry. 1998;59 suppl 20:22-33.

24. Dvorak RD, Wray TB, Kuvaas NJ, Kilwein TM. Mania and sexual risk: Associations with behavioral self-regulation. J Affect Disord. 2013;150:1076-81.

25. Di Nicola M, Tedeschi D, Mazza M, Martinotti G, Harnic D, Catalano V, et al. Behavioural addictions in bipolar disorder patients: role of impulsivity and personality dimensions. J Affect Disord. 2010;125(1-3):82-8.

26. Carnes PJ. Sexual addiction screening test. Tenn Nurse. 1991;54: 29.

27. Williams K, Reynolds MF. Sexual dysfunction in major depression. CNS Spectr. 2006;11(suppl S9):19-23.

28. Mathew RJ, Largen JL, Claghorn JL. Biological symptoms of depression. Psychosom Med. 1979;41:439-43.

29. Mathew RJ, Weinman ML. Sexual dysfunctions in depression. Arch Sex Behav. 1982;11:323-8.

30. Martin LA, Neighbors HW, Griffith DM. The experience of symptoms of depression in men vs women: analysis of the national comorbidity survey replication. JAMA Psychiatry. 2013;70:1100-6.

31. Schultz K, Hook JN, Davis DE, Penberthy JK, Reid RC. Nonparaphilic hypersexual behavior and depressive symptoms: a meta-analytic review of the literature. J Sex Marital Ther. 2014;40: 477-87. 
32. Kafka MP. The monoamine hypothesis for the pathophysiology of paraphilic disorders: an update. In: Prentky R, Janus E, Seto M, Burgess AW, editors. Sexually coercive behavior: understanding and management. 989. New York: New York Academy of Sciences; 2003. p. 86-94.

33. Benazzi F. Is 4 days the minimum duration of hypomania in bipolar II disorder? Eur Arch Psychiatry Clin Neurosci. 2001;251:32-4.

34. Judd LL, Akiskal HS. The prevalence and disability of bipolar spectrum disorders in the US population: a re-analysis of the ECA database taking into account subthreshold cases. J Affect Disord. 2003;73:123-31.

35. Hoertel N, Le Strat Y, Angst J, Dubertret C. Subthreshold bipolar disorder in a U.S. national representative sample: prevalence, correlates and perspectives for psychiatric nosography. J Affect Disord. 2013;25:338-47.
36. Sheehan DV, Lecrubier Y, Harnett-Sheehan K, Janavs J, Weiller E, Bonora I, et al. M.I.N.I. International Neuropsychiatric Interview for ADHD Studies Version 6.0.02009. Available from: https:// medical-outcomes.com/index/miniforstudentsclinicians.

37. Fletcher K, Parker G, Paterson A, Synnott H. High-risk behaviour in hypomanic states. J Affect Disord. 2013;150(1):50-6.

38. von Franque F, Klein V, Briken P. Which techniques are used in psychotherapeutic interventions for nonparaphilic hypersexual behavior? Sex Med Rev J. 2015;1:3-10.

39. Naficy H, Samenow CP, Fong TW. A review of pharmacological treatments for hypersexual disorder. Sex Addict Compulsivity. 2013;20(1/2):139-53. 